The Journal of Animal \& Plant Sciences, 31(2): 2021, Page: 480-487

ISSN (print): 1018-7081; ISSN (online): 2309-8694

\title{
EFFECTS OF LATE QUATERNARY AND CONTEMPORARY CLIMATES ON ECOREGIONAL PLANT DIVERSITY ACROSS DIFFERENT BIOMES
}

\author{
Chun-Jing Wang ${ }^{1,2}$, Zhi-Xiang Zhang ${ }^{3}$, and Yong-Kun Zhang ${ }^{*}$ \\ ${ }^{1}$ State Key Laboratory of Plateau Ecology and Agriculture, Qinghai University, Xining 810016, China \\ ${ }^{2}$ College of Agriculture and Animal Husbandry, Qinghai University, Xining 810016, China \\ ${ }^{3}$ School of Nature Conservation, Beijing Forestry University, Beijing 100083, China \\ "Corresponding Author's E-mail: zhangyongkun321@163.com
}

\begin{abstract}
Large-scale patterns of plant diversity and their determinants are central issues in macroecology and biodiversity conservation. Previous studies have shown that late Quaternary and contemporary climates can affect plant diversity at large scale. The main objective of our study was to explore the effects of late Quaternary and contemporary climates on ecoregional plant diversity (EPD). Here, we used global ecoregions to examine characteristic and geographically distinct features of plant diversity and quantified the joint and independent explanatory power of late Quaternary and contemporary climates to account for EPD across different biomes. Then, we tested environmental mean and heterogeneity hypotheses and found that both late Quaternary and contemporary climates (temperature and precipitation) can affect plant diversity at ecoregional scales. Furthermore, environmental heterogeneity (i.e., the heterogeneity of late Quaternary and contemporary climates) may have stronger explanatory power than environmental mean for EPD. However, climatic effects on EPD may depend on biome variation. The effects of late Quaternary and contemporary climates on EPD can persist widely in forest biomes and Temperate Grasslands, Savannas \& Shrublands. The results of the current study inform the prediction of plant diversity under future climate change, and support long-term monitoring of plant diversity at ecoregional scales.
\end{abstract}

Keywords: current climate; ecoregion; forest biome; globe; historical climate; plant richness.

https://doi.org/10.36899/JAPS.2021.2.0237

Published online October 03,2020

\section{INTRODUCTION}

Plant diversity makes a large contribution to the conservation of ecosystem functions and the maintenance of ecosystem services that are important to human beings (Hooper and Vitousek, 1997; Grime, 1998; Isbell et al., 2011; Wan et al., 2014). Ecoregions cover relatively large areas of land and, in their natural state, include characteristic, geographically distinct features of plant diversity (Olson et al., 2001; Wang and Wan, 2018). Many studies (Kier et al., 2005; van Vuuren et al., 2006; Blarquez et al., 2014; Wan et al., 2018a; 2019) have explored mechanisms of geographical influence on ecoregional plant diversity (EPD). Climate change may increase plant species richness across different temporal and spatial scales (Suggitt et al., 2019), and Kier et al. (2005) have indicated that human influence may be the driver of plant diversity in terrestrial ecoregions at large scale due to the loss and degradation of natural habitats and ecosystems. Wan et al. (2018) have shown that soil variation can be a good indicator of EPD around the world. Using these studies on mechanisms driving EPD through climate change and human activities, it is possible to inform biodiversity conservation and ecological modeling. For example, current and future plant diversity could be projected at large scales based on the known mechanisms driving the relationships between environmental changes and biodiversity.

Plant diversity displays distinct large-scale geographic patterns, which in turn are determined by late Quaternary and contemporary climatic conditions, both together and independently (e.g., Svenning, 2003; Kreft and Jetz, 2007; Sommer et al., 2010; Sandel et al., 2011; Wang et al., 2012a; Liu et al., 2018). A core hypothesis of biodiversity is that contemporary climates determine current plant diversity (O'brien et al., 2000; Ackerly et al., 2010; Kimball et al., 2010). In other words, there are significant relationships between contemporary climates and plant diversity at large scale. However, these patterns are only indicative of the equilibrium of climate and plant diversity spanning spatial and temporal scales (Svenning et al., 2015; Wang and Wan, 2019). Numerous studies (e.g., Sandel et al., 2011; Svenning and Sandel, 2013; Liu et al., 2018; Wan et al., 2018b) have indicated that there may be lags in the migration of species at continental to landscape scales under past climate change (Svenning et al., 2015). For example, tree species may exhibit a time delay in range response to climatic change due to timelagged dispersal and extended lifecycles (Sandel et al., 2011; Svenning et al., 2015; Wan et al., 2017). Instability in the climate of the late Quaternary may have influenced contemporary plant diversity, which could have led to the 
time-delay observed in relationships between climates and plant diversity at large scales (Sandel et al., 2011; Svenning et al., 2015; Wang and Wan, 2019). However, few studies have paid attention to the effects of Late Quaternary and contemporary climates on EPD. Therefore, we first asked whether late Quaternary and contemporary climates affect the pattern of plant diversity, together and independently, at large scale.

Here, we quantified late Quaternary and contemporary climates at ecoregional scales based on environmental mean and heterogeneity hypotheses. The environmental mean hypothesis indicates that the mean climatic conditions over a specific area (e.g., an ecoregion) filter for a set of plant species by optimizing their growth and distribution (Kraft et al., 2015; Stark et al., 2017). In contrast to the environmental mean hypothesis, large-scale environmental heterogeneity can affect the ability of different plant species to persist under environmental change within a specific area. EPD may instead be related to the degree of climatic heterogeneity in ecoregions around the world (Lundholm, 2009; Tamme et al., 2010; Stein et al., 2014; Stark et al., 2017).

Biomes are distinct plant communities that have formed in response to particular climates and they shape different distribution patterns of plant diversity at large scale (Olson et al., 2001). The environmental mean (i.e., one consistent physical climate) may be related to plant diversity across different biomes (Kier et al., 2005; Kraft et al., 2015; Jiang et al., 2017). By contrast, Stein et al. (2014) have shown that environmental heterogeneity may be a universal driver of species richness across taxa, biomes, and spatial scales. Plant diversity may depend in particular on the heterogeneity of climate and vegetation differences (Stein et al., 2014; Stein and Kreft, 2015). Hence, our second question was whether biome changes can affect the relationships between late Quaternary and contemporary climates and plant diversity at ecoregional scales. To address these questions, we used data on EPD and late Quaternary and contemporary climates across different biomes. Then, we quantified the explanatory power of climates for EPD across a variety of biomes. This explanatory power was compared across late Quaternary and contemporary climates in different biomes. Our study could support the establishment of a long-term monitoring system for plant diversity at large scales.

\section{MATERIALS AND METHODS}

Ecoregional plant diversity and biome: We downloaded the map of 867 ecoregions from the study of Olson et al. (2001; https://www.worldwildlife.org/publications/terrestrialecoregions-of-the-world). These ecoregions are delineated by consistent environmental conditions. Kier et al. (2005) used published records to quantify vascular plant species richness across global ecoregions. In our study, we used vascular plant species richness as an indicator of EPD, downloaded from the study by Kier et al. (2005). Plant species richness data with good or moderate quality was used to address the research questions in this study. Based on the study of Kier et al. (2005), the 206 ecoregions with good or moderate data quality, representing 11 biomes, were included in the analyses. Ecoregion area effects were excluded from the analysis, based on findings by Kier et al. (2005). Details of ecoregion and biome data are shown in Fig. 1.

Climate data: We obtained contemporary climate projections (1950-2000 AD averages) for mean annual temperature (MAT) and mean annual precipitation (MAP) at 5.0 arc-minutes resolution from the Worldclim database (http://www.worldclim.org/). We obtained paleoclimate data from the CCSM4 general circulation model. The CCSM4 model consists of a coupled atmospheric, ocean, and sea ice model with noninteractive vegetation (http://www.cesm.ucar.edu/models/ccsm4.0/). The model includes variations in orbital configuration, greenhouse gases, ice-sheet topography, and coincident sea level changes and bathymetry for paleoclimates (http://www.cesm.ucar.edu/models/ccsm4.0/). The grid size used for paleoclimate data was the same as for the contemporary climate, and the MAT and MAP of the paleoclimate were also downloaded from the Worldclim database (http://www.worldclim.org/). We computed the mean and standard deviation (SD) values of grids within each ecoregion according to the MAT and MAP of contemporary climates and paleoclimates, respectively (Stark et al., 2017), to test the hypotheses that EPD is related to environmental mean and heterogeneity.

Modeling and statistical analysis: First, we used partial linear regression modeling to analyze, respectively, the joint explanatory power of late Quaternary climates, the contemporary climate, and both late Quaternary and contemporary climates for EPD, including the mean and SD values of MAT and MAP of grids within each ecoregion (Graham, 2003). This analysis was conducted across 11 biomes. The explanatory power of both late Quaternary and contemporary climates was estimated as the adjusted $\mathrm{R}^{2}$ adj $(\%)$ value of partial linear regression modeling. The $\mathrm{R}_{\text {adj }}^{2}(\%)$ values of partial linear regression modeling were considered significant only when $P$-values $<0.05$ (Nagelkerke, 1991).

Linear regression modeling was used to explore the independent explanatory power of late Quaternary and contemporary climates (i.e., the mean and SD of MAT and MAP) for EPD across 11 biomes (Graham, 2003; Liu et al., 2018). The $\mathrm{R}^{2}$ adj $(\%)$ values with $P$ values $<0.05$ were used to quantify the independent explanatory power of each climate variable for EPD. Finally, we compared those average $\mathrm{R}^{2}$ adj $(\%)$ values with 
$P$-values $<0.05$ among the 11 biomes (Nagelkerke, 1991). All analyses were conducted in JMP 11.0 (SAS Institute Inc., Cary, NC, USA) and R software (https://www.r-project.org/).

\section{RESULTS}

The explanatory power of the late Quaternary climate, the contemporary climate, and the late Quaternary and contemporary climates together was $30.2 \%, 36.7 \%$, and $36.5 \%$, respectively $(P<0.05$; Table 1). These three climate scenarios exhibited significant relationships with the EPD of Tropical \& Subtropical Moist Broadleaf Forests, Topical \& Subtropical Dry Broadleaf Forests (significantly related only to contemporary climates and the combination of both climates), Tropical \& Subtropical Coniferous Forests, Temperate Broadleaf \& Mixed Forests, Temperate Conifer Forests (significantly related only to contemporary climates and the combination of both climates), Boreal Forests/Taiga, and Temperate Grasslands, Savannas \& Shrublands (Table 1). The late Quaternary climate was most significantly related to the EPD of Boreal Forests/Taiga (41.8\%; $P<0.05$; Table 1). The contemporary climate was most significantly related to the EPD of Temperate Grasslands, Savannas \&
Shrublands (50.4\%; $P<0.05$; Table 1). The combination of late Quaternary and contemporary climates was most significantly related to the EPD of Tropical \& Subtropical Dry Broadleaf Forests $(70.6 \% ; P<0.05$; Table 1$)$.

For EPD, the average independent explanatory powers of the SD of climates (i.e., MAT and MAP) were larger than those of mean climate for both late Quaternary and contemporary climate scenarios (Table 2 ). We found that the mean MAT of the late Quaternary and contemporary scenarios explained $13.9 \%$ and $6.4 \%$ $(P<0.05)$ of the EPD in Tropical \& Subtropical Moist Broadleaf Forests, and the independent explanatory power of the mean MAP of the late Quaternary and contemporary scenarios was $7.2 \%$ and $20.6 \%(P<0.05)$ for the EPD of Boreal Forests/Taiga and Temperate Broadleaf \& Mixed Forests, respectively (Table 2). The SD of the MAT of late Quaternary and contemporary scenarios significantly predicted the EPD of Tropical \& Subtropical Moist Broadleaf Forests, Temperate Broadleaf \& Mixed Forests, Boreal Forests/Taiga, and Temperate Grasslands, Savannas \& Shrublands $(P<$ 0.05 ), and the SD of the MAP of late Quaternary and contemporary scenarios significantly predicted the EPD of Tropical \& Subtropical Moist Broadleaf Forests and Temperate Grasslands, Savannas \& Shrublands $(P<0.05$; Table 2).

Table 1. Joint explanatory power of late Quaternary and contemporary climates for ecoregional plant diversity (EPD).

\begin{tabular}{ccccccc}
\hline & \multicolumn{2}{c}{ Late Quaternary } & \multicolumn{2}{c}{ Contemporary } & \multicolumn{2}{c}{ Both } \\
\hline & $\mathrm{R}^{2}(\%)$ & $P$-values & $\mathrm{R}^{2}(\%)$ & $P$-values & $\mathrm{R}^{2}(\%)$ & $P$-values \\
\hline TSMBF & $\mathbf{3 0 . 3 0}$ & $\mathbf{0 . 0 0}$ & $\mathbf{2 8 . 6 0}$ & $\mathbf{0 . 0 0}$ & $\mathbf{4 9 . 5 0}$ & $\mathbf{0 . 0 0}$ \\
TSDBF & 0.00 & 0.77 & 19.60 & 0.24 & $\mathbf{7 0 . 6 0}$ & $\mathbf{0 . 0 2}$ \\
TBMF & $\mathbf{2 8 . 8 0}$ & $\mathbf{0 . 0 0}$ & $\mathbf{4 9 . 2 0}$ & $\mathbf{0 . 0 0}$ & $\mathbf{5 6 . 1 0}$ & $\mathbf{0 . 0 0}$ \\
TCF & 13.80 & 0.12 & $\mathbf{3 4 . 4 0}$ & $\mathbf{0 . 0 0}$ & $\mathbf{3 5 . 6 0}$ & $\mathbf{0 . 0 2}$ \\
BF & $\mathbf{4 1 . 8 0}$ & $\mathbf{0 . 0 1}$ & $\mathbf{4 8 . 6 0}$ & $\mathbf{0 . 0 0}$ & $\mathbf{6 4 . 6 0}$ & $\mathbf{0 . 0 0}$ \\
TSGSS & $\mathbf{4 2 . 9 0}$ & $\mathbf{0 . 0 4}$ & 35.00 & 0.08 & 44.20 & 0.15 \\
TGSS & $\mathbf{4 0 . 5 0}$ & $\mathbf{0 . 0 0}$ & $\mathbf{5 0 . 4 0}$ & $\mathbf{0 . 0 0}$ & $\mathbf{4 4 . 8 0}$ & $\mathbf{0 . 0 1}$ \\
MGS & 6.20 & 0.52 & 10.70 & 0.45 & 58.50 & 0.58 \\
TD & 5.20 & 0.39 & 13.70 & 0.17 & 23.10 & 0.14 \\
MFWS & 0.00 & 0.88 & 0.00 & 0.82 & 0.00 & 0.94 \\
DXS & 8.90 & 0.20 & 0.00 & 0.58 & 20.30 & 0.09 \\
Overall & $\mathbf{3 0 . 2 0}$ & $\mathbf{0 . 0 0}$ & $\mathbf{3 6 . 7 0}$ & $\mathbf{0 . 0 0}$ & $\mathbf{3 6 . 5 0}$ & $\mathbf{0 . 0 0}$ \\
\hline
\end{tabular}

Values of $\mathrm{R}^{2}(\%)$ represent the adjusted $\mathrm{R}^{2} \mathrm{adj}(\%)$ of linear regression modeling to determine the joint explanatory power of late Quaternary and contemporary climates for EPD. Late Quaternary, Contemporary, and Both represents late Quaternary climate, contemporary climate, and late Quaternary and contemporary climates together, respectively. Overall represents the results of linear regression modeling based on all the ecoregions. The biomes used in this table are defined as follows:TSMBF: Tropical \& Subtropical Moist Broadleaf Forests; TSDBF:
Tropical \& Subtropical Dry Broadleaf Forests; TBMF: Temperate Broadleaf \& Mixed Forests; TCF: Temperate Conifer Forests; BF: Boreal Forests/Taiga; TSGSS: Tropical \& Subtropical Grasslands, Savannas \& Shrublands; TGSS: Temperate Grasslands, Savannas \& Shrublands; MGS: Montane Grasslands \& Shrublands; TD: Tundra; MFWS: Mediterranean Forests, Woodlands \& Scrub; DXS: Deserts \& Xeric Shrublands. We highlight significant variables $(P<0.05)$ with bold font. 
Table 2. Independent explanatory power of late Quaternary and contemporary climates for ecoregional plant diversity (EPD) based on the environmental mean and heterogeneity hypotheses.

\begin{tabular}{|c|c|c|c|c|c|c|c|c|c|c|c|c|c|c|c|c|}
\hline \multirow[b]{3}{*}{ Biome } & \multicolumn{8}{|c|}{ Late Quaternary } & \multicolumn{8}{|c|}{ Contemporary } \\
\hline & \multicolumn{2}{|c|}{ Mean MAT } & \multicolumn{2}{|c|}{ SD MAT } & \multicolumn{2}{|c|}{ Mean MAP } & \multicolumn{2}{|c|}{ SD MAP } & \multicolumn{2}{|c|}{ Mean MAT } & \multicolumn{2}{|c|}{ SD MAT } & \multicolumn{2}{|c|}{ Mean MAP } & \multicolumn{2}{|c|}{ SD MAP } \\
\hline & $\begin{array}{l}R^{2} \\
(\%)\end{array}$ & $P$-values & $\begin{array}{l}R^{2} \\
(\%)\end{array}$ & $P$-values & $\begin{array}{l}\mathbf{R}^{2} \\
(\%)\end{array}$ & $P$-values & $\begin{array}{l}R^{2} \\
(\%)\end{array}$ & $P$-values & $\begin{array}{l}R^{2} \\
(\%)\end{array}$ & $P$-values & $\begin{array}{l}R^{2} \\
(\%)\end{array}$ & $P$-values & $\begin{array}{l}\mathbf{R}^{2} \\
(\%)\end{array}$ & $P$-values & $\begin{array}{l}R^{2} \\
(\%)\end{array}$ & $P$-values \\
\hline TSMBF & 13.91 & 0.00 & 21.01 & 0.00 & 0.00 & 0.32 & 19.26 & 0.00 & 6.42 & 0.01 & 19.87 & 0.00 & 1.06 & 0.17 & 22.55 & 0.00 \\
\hline TSDBF & 0.00 & 0.50 & 0.00 & 0.87 & 0.00 & 0.62 & 0.00 & 0.40 & 7.43 & 0.15 & 0.00 & 0.98 & 0.00 & 0.42 & 2.56 & 0.25 \\
\hline TBMF & 0.00 & 0.94 & 18.49 & 0.00 & 3.54 & 0.11 & 0.00 & 0.35 & 0.00 & 0.47 & 42.37 & 0.00 & 7.22 & 0.04 & 0.00 & 0.66 \\
\hline $\mathrm{TCF}$ & 7.14 & 0.07 & 2.54 & 0.18 & 0.00 & 0.86 & 0.00 & 0.67 & 1.91 & 0.21 & 24.43 & 0.00 & 0.00 & 0.99 & 0.00 & 0.77 \\
\hline $\mathrm{BF}$ & 0.44 & 0.31 & 32.02 & 0.00 & 20.57 & 0.02 & 8.88 & 0.09 & 0.00 & 0.38 & 34.53 & 0.00 & 2.10 & 0.23 & 2.59 & 0.22 \\
\hline TSGSS & 0.00 & 0.37 & 0.00 & 0.41 & 11.10 & 0.10 & 0.00 & 0.43 & 3.97 & 0.22 & 0.00 & 0.48 & 11.30 & 0.10 & 0.00 & 0.82 \\
\hline TGSS & 0.00 & 0.88 & 31.21 & 0.00 & 2.76 & 0.20 & 22.59 & 0.01 & 0.00 & 0.59 & 49.26 & 0.00 & 7.65 & 0.08 & 25.32 & 0.00 \\
\hline MGS & 8.63 & 0.16 & 0.00 & 0.83 & 0.00 & 0.43 & 0.00 & 0.88 & 9.37 & 0.15 & 0.00 & 0.79 & 0.00 & 0.61 & 0.00 & 0.79 \\
\hline TD & 0.00 & 0.96 & 0.00 & 0.96 & 0.00 & 0.37 & 0.00 & 0.82 & 0.00 & 0.68 & 0.85 & 0.28 & 2.63 & 0.20 & 1.21 & 0.26 \\
\hline MFWS & 0.00 & 0.34 & 0.00 & 0.67 & 0.00 & 0.92 & 0.00 & 0.46 & 3.52 & 0.25 & 0.00 & 0.62 & 0.00 & 0.93 & 0.00 & 0.41 \\
\hline DXS & 0.00 & 0.10 & 2.75 & 0.16 & 0.00 & 0.42 & 0.97 & 0.25 & 2.35 & 0.18 & 0.23 & 0.31 & 0.00 & 0.86 & 0.00 & 0.53 \\
\hline $\begin{array}{c}\text { Avg. } \\
(P<0.05)\end{array}$ & 13.91 & & 25.68 & & 20.57 & & 20.93 & & 6.42 & & 34.09 & & 7.22 & & 23.94 & \\
\hline
\end{tabular}

Values of $\mathrm{R}^{2}(\%)$ represent the adjusted $\mathrm{R}^{2}$ adj (\%) of linear regression modeling to determine the independent explanatory power of late Quaternary and contemporary climates for EPD. Late Quaternary and Contemporary represents late Quaternary and contemporary climates, respectively. Avg. $(P<0.05)$ represents average adjusted $\mathrm{R}^{2}$ adj $(\%)$ values with $P$ values $<0.05$ among the 11 biomes. Codes of biomes used in this table are defined as follows: TSMBF: Tropical \& Subtropical Moist Broadleaf Forests; TSDBF: Tropical \& Subtropical Dry Broadleaf Forests; TBMF: Temperate Broadleaf \& Mixed Forests; TCF: Temperate Conifer Forests; BF: Boreal Forests/Taiga; TSGSS: Tropical \& Subtropical Grasslands, Savannas \& Shrublands; TGSS: Temperate Grasslands, Savannas \& Shrublands; MGS: Montane Grasslands \& Shrublands; TD: Tundra; MFWS: Mediterranean Forests, Woodlands \& Scrub; DXS: Deserts \& Xeric Shrublands. We highlight significant variables $(P<0.05)$ with bold font. 


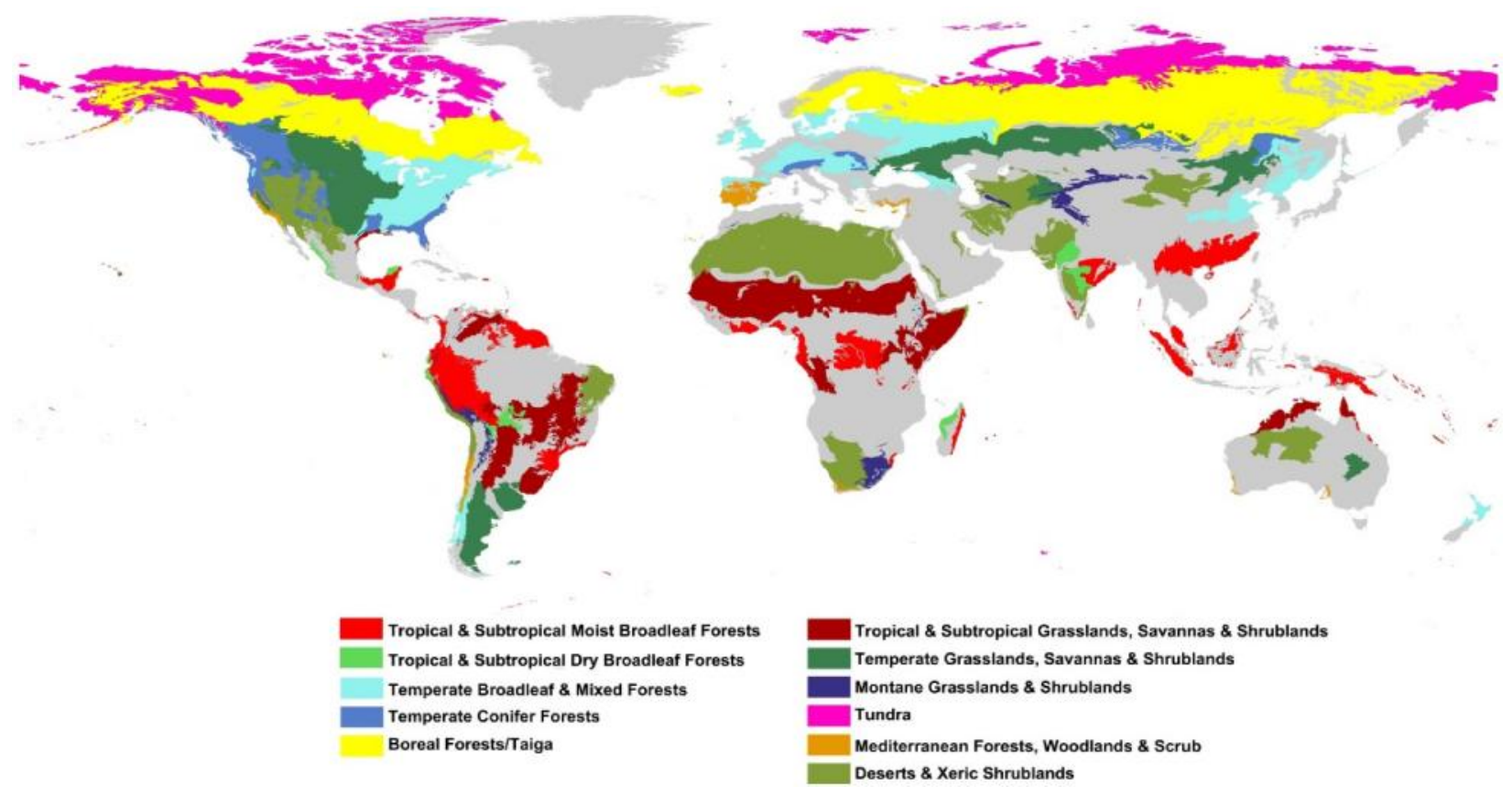

Fig. 1. Ecoregions included in this study, representing 11 biomes (Olson et al., 2001).

\section{DISCUSSION}

Our results, that the explanatory power of the late Quaternary climate, contemporary climate, and late Quaternary and contemporary climates together was $30.2 \%, 36.7 \%$, and $36.5 \%$, respectively $(P<0.05$; Table 1), indicated that both the late Quaternary and contemporary climates (represented as MAT and MAP) are significant predictors of plant diversity at ecoregional scales (Tables 1 and 2). Furthermore, such EPD patterns may differ by biome because $\mathrm{R}^{2}$ varied largely depending on variables and biomes (Tables 1 and 2). It may be that 1) the large-scale pattern of plant diversity is determined by contemporary climates, or 2) historical climates may affect the pattern of plant diversity at large scale; our study supports both of these hypotheses. Some previous studies (e.g., O'brien et al., 2000; Ackerly et al., 2010; Kimball et al., 2010) have suggested that equilibrium in response to contemporary climatic conditions is plausible for large-scale patterns of plant diversity. Although contemporary climates exhibited a strong relationship with EPD, we should take both the late Quaternary and contemporary climates into consideration when evaluating EPD, depending on biome, due to the high joint explanatory power of both late Quaternary and contemporary climates together.

Our study tested the environmental mean and heterogeneity hypotheses for EPD across different biomes. The mean MAT of the late Quaternary and contemporary scenarios explained $13.9 \%$ and $6.4 \%(P<$ $0.05)$ of the EPD in Tropical \& Subtropical Moist Broadleaf Forests, and the independent explanatory power of the mean MAP of the late Quaternary and contemporary scenarios was $7.2 \%$ and $20.6 \%(P<0.05)$ for the EPD of Boreal Forests/Taiga and Temperate Broadleaf \& Mixed Forests, respectively (Table 2). According to the environmental mean hypothesis, mean climatic conditions over a given area can filter for a set of plant species. However, such filtering effects may be extremely weak at large scales (e.g., ecoregions) compared to small scales (i.e., communities; Kraft et al., 2015; Stark et al., 2017; Harrison et al., 2020). Plant diversity is determined by environmental filtering of the regional flora; local resource heterogeneity, resource partitioning, nutrient stoichiometry, or soil fertility may play small roles in realized patterns of plant diversity (Wang et al., 2009; Laliberté et al., 2014; Xu et al., 2018; Wan et al., 2018a; 2020). However, variation in climates may affect EPD within any specific ecoregion. Stein et al. (2014) have shown that environmental heterogeneity (e.g., annual seasonality in water availability, long-term climatic fluctuations) can drive plant diversity across different biomes. Although both the environmental mean and heterogeneity hypotheses may be supported by patterns of EPD, environmental heterogeneity (i.e., the MAT and MAP of the Quaternary and contemporary scenarios) may have stronger explanatory power for EPD than environmental mean.

We found that late Quaternary and contemporary climates were predictive of the EPD of most forest biomes except for Temperate Grasslands, Savannas \& Shrublands, indicating that late Quaternary and contemporary climates could drive plant diversity of forest biomes at ecoregional scales. Previous studies 
(e.g., Wang et al., 2009; Wang et al., 2012b; Xu et al., 2018) have shown that geographical extent has a large potential to affect the distribution pattern of tree diversity. With increasing geographical extent, the explanatory power of climate (i.e., water availability and temperature) increased for tree diversity, while the explanatory power of habitat heterogeneity and human activities decreased (Wang et al., 2012b; Wan et al., 2020). Human activities are the main determinant of EPD (Kier et al., 2005; Fedele et al., 2020). This, in combination with our results, indicates that, across increasing geographical extents up to ecoregional level, the explanatory power of climates could be strong for the EPD of forest biomes, but human activities may have a larger effect on EPD in biomes other than Temperate Grasslands, Savannas \& Shrublands.

Even longer time lags can occur for tree growth and migration under Quaternary glacial-interglacial climate change from local to global scales (Svenning, 2003; Svenning and Skov, 2007). Meanwhile, contemporary water availability plays an important role in tree diversity at large scales, and tree spring growth, water use, and successional strategy are very sensitive to contemporary temperature changes (O'brien et al., 2000; Kreft and Jetz 2007; Wang et al., 2012b; Stein et al., 2014). Hence, late Quaternary and contemporary climates could contribute to patterns of EPD across forest biomes. Two factors may lead to the particularly strong effects of climates on the EPD of Temperate Grasslands, Savannas \& Shrublands: 1) disturbance by wildfire and growth responses to changing $\mathrm{CO}_{2}$ levels may increase grass dominance in some shrublands under late Quaternary to contemporary climate change (Midgley and Bond, 2015; Li et al., 2020); and 2) the climatic spaces of Temperate Grasslands, Savannas \& Shrublands could be particularly closely related to annual mean temperature and total precipitation (Jiang et al., 2017; García Criado et al., 2020).

We should pay attention to the influence of late Quaternary temperature and precipitation on EPD across different biomes (e.g., Boreal Forests/Taiga). At large scales, plant species ranges may response slowly to glacial-interglacial climate cycles, and could be heavily influenced by extinction and immigration lags in forest biomes (e.g., Temperate Broadleaf \& Mixed Forests and Tropical \& Subtropical Moist Broadleaf Forests; Svenning, 2003; Svenning and Skov, 2007; Svenning and Sandel, 2013). Furthermore, a time lag would be expected before plant richness in the novel condition reaches an equilibrium, via in situ diversification and adaptation to late Quaternary climates (Svenning et al., 2015). The heterogeneity of late Quaternary climates could lead to a variety of habitats within ecoregions. Ecoregions with multiple habitat types could lead to rich plant diversity in forest biomes (e.g., Tropical \& Subtropical Moist Broadleaf Forests; Amici et al., 2015).
In conclusion, our study provided evidence that the temperature and precipitation of late Quaternary and contemporary scenarios are related to EPD across global forest biomes, with particularly strong relationships to the EPD of Temperate Grasslands, Savannas \& Shrublands. Furthermore, the heterogeneity of late Quaternary and contemporary climates plays an important role in patterns of EPD across different biomes. Hence, it is necessary to take both late Quaternary and contemporary climates into consideration for future studies of plant diversity at ecoregional scales. Our study will help to provide accurate prediction of the responses of plant species assemblages to future climate change. We provide theoretical underpinnings for the conservation of plant diversity at ecoregional scales, and our study supports the establishment of a long-term monitoring system for plant diversity at large scales.

Acknowledgements: We thank the useful comments of two reviewers for the improvement on previous manuscript. This work has been supported by the Basic Research Project of Qinghai Province, China (2020-ZJ967Q) and the National Natural Science Foundation of China (31800464).

\section{REFERENCES}

Ackerly, D.D., S.R. Loarie, W.K. Cornwell, S.B. Weiss, H. Hamilton, R. Branciforte, and N.J.B. Kraft (2010). The geography of climate change: implications for conservation biogeography. Divers. Distrib. 16: 476-487. http://dx.doi.org/10.1111/j.14724642.2010.00654.x

Amici, V., D. Rocchini, G. Filibeck, G. Bacaro, E. Santi, F. Geri, S. Landi, A. Scoppola, and A. Chiarucci (2015). Landscape structure effects on forest plant diversity at local scale: exploring the role of spatial extent. Ecol. Complexity 21: 44-52. http://dx.doi.org/10.1016/j.ecocom.2014.12.004

Blarquez, O., C. Carcaillet, T. Frejaville, and Y. Bergeron (2014). Disentangling the trajectories of alpha, beta and gamma plant diversity of North American boreal ecoregions since 15,500 years. Front. Ecol. Evol. 2: 6. http://dx.doi.org/10.3389/fevo.2014.00006

Fedele, G., C. Donatti, C. Harvey, L. Hannah, and D. Hole (2020). Limited use of transformative adaptation in response to social-ecological shifts driven by climate change. Ecol. Soc. 25: 25. https://doi.org/10.5751/ES-11381-250125

García Criado, M., I.H. Myers-Smith, A.D. Bjorkman, C.E. Lehmann, and N. Stevens (2020). Woody plant encroachment intensifies under climate change across tundra and savanna biomes. Global Ecol.

Biogeogr. 
https://doi.org/10.1111/geb.13072

Graham, M.H. (2003). Confronting multicollinearity in ecological multiple regression. Ecology 84: 2809-2815. http://dx.doi.org/10.2307/3449952

Grime, J.P. (1998). Benefits of plant diversity to ecosystems: immediate, filter and founder effects. J. Ecol. 86: 902-910. http://dx.doi.org/10.1046/j.13652745.1998.00306.x

Harrison, S., M.J. Spasojevic, and D. Li (2020). Climate and plant community diversity in space and time. Proc. Natl. Acad. Sci. U.S.A. 117: 4464-4470. https://doi.org/10.1073/pnas.1921724117

Hooper, D.U. and P.M. Vitousek (1997). The effects of plant composition and diversity on ecosystem processes. Science 277: 1302-1305. http://dx.doi.org/10.1126/science.277.5330.1302

Isbell, F., V. Calcagno, A. Hector, J. Connolly, W.S. Harpole, P.B. Reich, M. Scherer-Lorenzen, B. Schmid, D. Tilman, J. van Ruijven, A. Weigelt, B.J. Wilsey, E.S. Zavaleta, and A. Weigelt (2011). High plant diversity is needed to maintain ecosystem services. Nature 477: 199. http://dx.doi.org/10.1038/nature10282

Jiang, M., B.S. Felzer, U.N. Nielsen, and B.E. Medlyn (2017). Biome-specific climatic space defined by temperature and precipitation predictability. Global Ecol. Biogeogr. 26: 1270-1282. http://dx.doi.org/10.1111/geb.12635

Kier, G., J. Mutke, E. Dinerstein, T.H. Ricketts, W. Küper, H. Kreft, and W. Barthlott (2005). Global patterns of plant diversity and floristic knowledge. J. Biogeogr. 32: 1107-1116. https://doi.org/10.1111/j.1365-2699.2005.01272.x

Kimball, S., A.L. Angert, T.E. Huxman, and D.L. Venable (2010). Contemporary climate change in the Sonoran Desert favors cold-adapted species. Global Change Biol. 16: 1555-1565. http://dx.doi.org/10.1111/j.13652486.2009.02106.x

Kraft, N.J., P.B. Adler, O. Godoy, E.C. James, S. Fuller, and J.M. Levine (2015). Community assembly, coexistence and the environmental filtering metaphor. Funct. Ecol. 29: 592-599. http://dx.doi.org/10.1111/1365-2435.12345

Kreft, H. and W. Jetz (2007). Global patterns and determinants of vascular plant diversity. P. Nat. Acad. Sci. 104: 5925-5930. http://dx.doi.org/10.1073/pnas.0608361104

Laliberté, E., G. Zemunik, and B.L. Turner (2014). Environmental filtering explains variation in plant diversity along resource gradients. Science 345: 1602-1605. http://dx.doi.org/10.1126/science. 1256330

Li, M., X. Zhang, B. Niu, Y. He, X. Wang, and J. Wu (2020). Changes in plant species richness distribution in Tibetan alpine grasslands under different precipitation scenarios. Global Ecol. Conserv. 21: e00848. https://doi.org/10.1016/j.gecco.2019.e00848

Liu, Y., X. Su, N. Shrestha, X. Xu, S. Wang, Y. Li, Q. Wang, D. Sandanov, and Z. Wang (2018). Effects of contemporary environment and Quaternary climate change on drylands plant diversity differ between growth forms. Ecography 41: 1-12. http://dx.doi.org/10.1111/ecog.03698

Lundholm, J.T. (2009). Plant species diversity and environmental heterogeneity: spatial scale and competing hypotheses. J. Veg. Sci. 20: 377-391. http://dx.doi.org/10.1111/j.16541103.2009.05577.x

Midgley, G.F. and W.J. Bond (2015). Future of African terrestrial biodiversity and ecosystems under anthropogenic climate change. Nat. Clim. Change 5: 823. http://dx.doi.org/10.1038/nclimate2753

Nagelkerke, N.J. (1991). A note on a general definition of the coefficient of determination. Biometrika 78: 691-692. http://dx.doi.org/10.2307/2337038

O'brien, E.M., R. Field, and R.J. Whittaker (2000). Climatic gradients in woody plant (tree and shrub) diversity: water-energy dynamics, residual variation, and topography. Oikos 89: 588-600. http://dx.doi.org/10.2307/3547645

Olson, D.M., E. Dinerstein, E.D. Wikramanayake, N.D. Burgess, G.V.N. Powell, E.C. Underwood, J.A. D'amico, I. Itoua, H.E. Strand, J.C. Morrison, C.J. Loucks, T.F. Allnutt, T.H. Ricketts, Y. Kura, J.F. Lamoreux, W.W. Wettengel, P. Hedao, and K.R. Kassem (2001). Terrestrial Ecoregions of the World: A New Map of Life on Earth A new global map of terrestrial ecoregions provides an innovative tool for conserving biodiversity. BioScience 51: 933-938. https://doi.org/10.1641/00063568(2001)051[0933:TEOTWA]2.0.CO;2

Sandel, B., L. Arge, B. Dalsgaard, R.G. Davies, K.J. Gaston, W.J. Sutherland, and J.C. Svenning (2011). The influence of Late Quaternary climate-change velocity on species endemism. Science 334(6056): 660-664. http://dx.doi.org/10.1126/science.1210173

Sommer, J.H., H. Kreft, G. Kier, W. Jetz, J. Mutke, and W. Barthlott (2010). Projected impacts of climate change on regional capacities for global plant species richness. P. Roy. Soc. B-Biol. Sci. 277: 2271-2280. http://dx.doi.org/10.1098/rspb.2010.0120

Stark, J., R. Lehman, L. Crawford, B.J. Enquist, and B. Blonder (2017). Does environmental heterogeneity drive functional trait variation? A test in montane and alpine meadows. Oikos 126: 
1650-1659. http://dx.doi.org/10.1111/oik.04311

Stein, A. and H. Kreft (2015). Terminology and quantification of environmental heterogeneity in species-richness research. Biol. Rev. 90: 815836. http://dx.doi.org/10.1111/brv.12135

Stein, A., K. Gerstner, and H. Kreft (2014). Environmental heterogeneity as a universal driver of species richness across taxa, biomes and spatial scales. Ecol. Lett. 17: 866-880. http://dx.doi.org/10.1111/ele.12277

Suggitt, A.J., D.G. Lister, and C.D. Thomas (2019). Widespread effects of climate change on local plant diversity. Curr. Biol. 29: 2905-2911. https://doi.org/10.1016/j.cub.2019.06.079

Svenning, J.C. (2003). Deterministic Plio-Pleistocene extinctions in the European cool-temperate tree flora. Ecol. Lett. 6: 646-653. http://dx.doi.org/10.1046/j.14610248.2003.00477.x

Svenning, J.C. and B. Sandel (2013). Disequilibrium vegetation dynamics under future climate change. Am. Bot. 100: 1266-1286. http://dx.doi.org/10.3732/ajb.1200469

Svenning, J.C. and F. Skov (2007). Ice age legacies in the geographical distribution of tree species richness in Europe. Global Ecol. Biogeogr. 16: 234-245. http://dx.doi.org/10.1111/j.14668238.2006.00280.x

Svenning, J.C., W.L. Eiserhardt, S. Normand, A. Ordonez, and B. Sandel (2015). The influence of paleoclimate on present-day patterns in biodiversity and ecosystems. Annu. Rev. Ecol. Evol. S. 46: 551-572. http://dx.doi.org/10.1146/annurev-ecolsys112414-054.314

Tamme, R., I. Hiiesalu, L. Laanisto, R. Szava-Kovats, and M. Pärtel (2010). Environmental heterogeneity, species diversity and co-existence at different spatial scales. J. Veg. Sci. 21: 796801. http://dx.doi.org/10.1111/j.16541103.2010.01185.x

van Vuuren, D.P., O.E. Sala, and H.M. Pereira (2006). The future of vascular plant diversity under four global scenarios. Ecol. Soc. 11: 25. http://dx.doi.org/10.5751/es-01818-110225

Wan, J., C. Wang, J. Yu, S. Han, L. Wang, and Q. Wang (2014). The ability of Nature Reserves to conserve medicinal plant resources: A case study in northeast China. Ecol. Inform. 24: 27-34. https://doi.org/10.1016/j.ecoinf.2014.06.005

Wan, J.Z., Q.F. Li, N. Li, J.H. Si, Z.X. Zhang, C.J. Wang, X.L. Li, and Z.R. Li (2018a). Soil indicators of plant diversity for global ecoregions: Implications for management practices. Global Ecol. Conserv. 14: e00404. https://doi.org/10.1016/j.gecco.2018.e00404
Wan, J.Z. and C.J. Wang (2018). Expansion risk of invasive plants in regions of high plant diversity: a global assessment using 36 species. Ecol. Inform. 46: 8-18. https://doi.org/10.1016/j.ecoinf.2018.04.004

Wan, J.Z., C.J. Wang, H. Qu, R. Liu, and Z.X. Zhang (2018b). Vulnerability of forest vegetation to anthropogenic climate change in China. Sci. Total Environ. 621: 1633-1641. https://doi.org/10.1016/j.scitotenv.2017.10.065

Wan, J.Z., C.J. Wang, and F.H. Yu (2017). Spatial conservation prioritization for dominant tree species of Chinese forest communities under climate change. Climatic Change 144: 303-316. https://doi.org/10.1007/s10584-017-2044-7

Wan, J.Z., C.J. Wang, and Z.X. Zhang (2020). Environmental predictors of vascular plant richness at large spatial scales based on protected area data of China. Global Ecol. Conserv. 21: e00846. https://doi.org/10.1016/j.gecco.2019.e00846

Wan, J.Z., J.H. Yu, G.J. Yin, Z.M. Song, D.X. Wei, and C.J. Wang (2019). Effects of soil properties on the spatial distribution of forest vegetation across China. Global Ecol. Conserv. 18: e00635. https://doi.org/10.1016/j.gecco.2018.e00404

Wang, C.J. and J.Z. Wan (2019). Historical and contemporary climate legacy of the large-scale distributional patterns of plant richness across different taxonomic levels: An assessment of protected areas in China. Bot. Sci. 97: 323-335. https://doi.org/10.17129/botsci.2211

Wang, Z., J.H. Brown, Z. Tang, and J. Fang (2009). Temperature dependence, spatial scale, and tree species diversity in eastern Asia and North America. P. Nat. Acad. Sci. 106: 13388-13392. http://dx.doi.org/10.1073/pnas.0905030106

Wang, Z., J. Fang, Z. Tang, and X. Lin (2012a). Relative role of contemporary environment versus history in shaping diversity patterns of China's woody plants. Ecography 35: 1124-1133. http://dx.doi.org/10.1111/j.16000587.2011.06781.x

Wang, Z., J. Fang, Z. Tang, and L. Shi (2012b). Geographical patterns in the beta diversity of China's woody plants: the influence of space, environment and range size. Ecography 35: 1092-1102. http://dx.doi.org/10.1111/j.16000587.2012.06988.x

Xu, W., J.C. Svenning, G. Chen, B. Chen, J. Huang, and K. Ma (2018). Plant geographical range size and climate stability in China: Growth form matters. Global Ecol. Biogeogr. 27: 506-517. http://dx.doi.org/10.1111/geb.12710. 